\title{
Saúde e relações de gênero: notas de um diário de campo sobre vivência de rua
}

\section{Health Care and Gender Relations: Field Diary notes Regarding Living on the Streets Salud y relaciones de género: notas de un diario de campo sobre la vida en la calle}

\author{
Adriane Roso, Verônica Bem Dos Santos* \\ Universidad Federal de Santa María
}

Doi: http://dx.doi.org/10.12804/revistas.urosario.edu.co/apl/a.3379

\section{Resumo}

Este artigo apresenta dados empíricos de uma pesquisa qualitativa que aborda a saúde das mulheres em vivência de rua e as transversalidades no cuidado em saúde. A produção dos dados apoiou-se na observação participante em ruas de uma cidade do interior do Rio Grande do Sul, Brasil. A criação de campos culturais guiou a análise: relação com a(o) Outra(o) na rua; relações de gênero; e relação com os serviços de atenção à saúde. A interpretação das informações baseou-se em uma abordagem psicossocial e em autores que estudam a população em vivência de rua representam. A conclusão indicou que as mulheres observadas em vivência de uma população bastante diversa em suas características e complexa em suas necessidades, demandando cuidados que levem em conta uma variedade de transversalidades, especialmente aquelas que se referem às interações e relações estabelecidas nos meios onde vivem.

Palavras-chave: saúde pública, mulheres, vivência de rua, integralidade em saúde.

\section{Abstract}

This article presents empirical data from a qualitative research which approaches the health of women who live on the street and the transversalities in the healthcare. The data production was supported by participant observation within the streets, in a country town from Rio Grande do Sul, Brazil. The creation of cultural fields guided the analysis: the relation with the Other on the street; gender relations; and relation with the healthcare services. The data interpretation was based on a psychosocial perspective and on authors that study homeless population. The conclusion indicated that the observed women living on the street represent a very diverse population in its characteristics and complex in its needs, demanding care that takes into account a variety of transversalities, especially those which refer to interactions and relations established within its boundaries.

Keywords: public health, women, homeless persons, integrality in health.

* Universidad Federal de Santa María. Correio electrônico: adrianeroso@gmail.com

Cómo citar este artículo: Roso, A., \& Dos Santos, V. B. (2017). Saúde e relações de gênero: notas de um diário de campo sobre vivência de rua. Avances en Psicología Latinoamericana, 35(2), 283-299. doi: http://dx.doi.org/10.12804/revistas.urosario. edu.co/apl/a.3379 


\section{Resumen}

Este artículo presenta datos empíricos de una investigación cualitativa que aborda la salud de las mujeres que viven en las calles y las transversalidades en el cuidado de la salud. La producción de los datos se apoyó en la observación participante en las calles de una ciudad del interior de Río Grande do Sul, Brasil. La creación de campos culturales guio el análisis: relación con la(el) otra(o) en las calles; relaciones de género; y relación con los servicios de atención a la salud. La interpretación de las informaciones estuvo basada en un abordaje psicosocial y en autores que estudian la población que vive en las calles. La conclusión indicó que las mujeres observadas que viven en las calles representan una población bastante diversa en sus características y compleja en sus necesidades, quienes demandan cuidados que tengan en cuenta una variedad de transversalidades, especialmente aquellas que se refieren a las interacciones y relaciones establecidas en los medios donde viven.

Palabras clave: salud pública, mujeres, vivir en las calles, integralidad en salud.

A reflexão delineada nesse artigo deriva da produção de uma dissertação de mestrado ${ }^{1}$, cujo objeto de análise foi a saúde das mulheres em vivência de rua. Adotamos a expressão "mulheres em vivência de rua" com o intuito de assinalar a experiência per se e não um possível aspecto situacional (como se elas precisassem ou desejassem incondicionalmente sair da situação de rua). Experiência no sentido de Bondía (2002), como aquilo que "nos passa, que nos acontece, o que nos toca. Não o que se passa, o que acontece, ou o que toca" (p. 21).

A pesquisa de mestrado envolveu uma intensa inserção das pesquisadoras em um campo espe-

1 Dissertação intitulada "Mulheres em vivência de rua e a integralidade no cuidado em saúde", defendida junto ao Programa de Pós-Graduação em Psicologia, da Universidade Federal de Santa Maria - UFSM. cífico - as ruas do centro de uma cidade de médio porte, localizada no interior do estado do Rio Grande do Sul (IBGE, 2014). O município dispõe de um serviço de acolhimento institucional para adultos em vivência de rua, que está situado na região central da cidade. Já o atendimento em saúde para essa população é disponibilizado nas Estratégias de Saúde da Família (ESF) convencionais, visto que o município não conta com ESFs específicas para População em Situação de Rua. Salientamos que esse serviço já existe em algumas cidades brasileiras.

A saúde das mulheres em vivência de rua foi escolhida como foco por entendermos que fazem parte de grupos minoritários, tendo seus direitos duplamente negligenciados. Por um lado, são excluídas porque vivem nas ruas e, por outro, têm sua saúde condicionada às relações não-equitativas de gênero. Ainda que em menor número nas ruas (Quiroga \& Novo, 2009; Tiene, 2014), de fato, "as mulheres em situação de rua constituem o grupo mais vulnerável de uma população que, pelas condições em que (sobre)vive, pode ser considerada nos limites inferiores de pobreza e vulnerabilidade" (Quiroga \& Novo, 2009, p.187). Buscamos discutir sobre alguns entrecruzamentos do cuidado em saúde dessas mulheres, os quais se referem às relações com a(o) Outra(o) na rua, e com os serviços de saúde e as relações de gênero. A inserção no campo de pesquisa, anotada em diário de campo, foi cerceada de inquietações de cunho ético e disparadora de questionamentos sobre a atenção à saúde a uma população, muitas vezes, de difícil acesso.

Concordamos com Villela (2000), que reconhece a dificuldade em definir exatamente o que venha a ser saúde. Sendo que "mais fácil é descrever as práticas sociais que se organizam em torno de sua ideia, buscando compreender seus determinantes e os sentidos que esta ideia assume para diferentes grupos, populações e períodos" (Villela, 2000, p.7). Em se tratando de mulheres que vivem nas ruas, as dificuldades se acentuam, pois os desafios 
são mais intensos. Estão vulneráveis à violência, "percebidas como "vítimas fáceis" e os cuidados com o corpo, saúde e higiene são extremamente precários (Quiroga \& Novo, 2009). Olhar para essa miríade de aspectos, entendemos, envolve compreender a atenção em saúde para além de um modo puramente focado no processo saúde-doença. Ou seja, envolve dirigir nossos esforços aos aspectos de uma saúde integral. A integralidade, definida como um dos princípios do Sistema Único de Saúde (SUS), e recentemente incluída como descritor em Ciências da Saúde pela Biblioteca Virtual da Saúde, quer dizer que "a atenção à saúde deve levar em consideração as necessidades específicas de pessoas ou grupos de pessoas, ainda que minoritárias em relação ao total da população" (Brasil, 2000, p. 31).

Mas como adensar mais ainda as discussões e a compreensão sobre atenção à saúde de mulheres em vivência de rua de modo a potencializar a integralidade? Tomamos emprestados os conceitos de instituição e transversalidade, propostos pela Análise Institucional, para compreender os diversos fatores que compõem os processos de saúde-doença. Instituição se configura como o cruzamento de diferentes instâncias - econômicas, políticas, ideológicas - formando a rede social que une e perpassa as pessoas. Desse modo, as instituições são sempre cruzadas por outras instituições em diversos níveis, portanto, podem ser compreendidas pela sua transversalidade (Altoé, 2004). A noção de transversalidade nos remete à "interpenetração entre diferentes forças instituídas" (Rocha \& Deusdará, 2010, p.57). Trabalhar a transversalidade, neste caso, corresponde a dar visibilidade aos diversos fatores capazes de produzir efeitos sobre as necessidades de saúde da população participante.

Os diversos temas capazes de produzir efeitos sobre as necessidades de saúde, impactando o modo como as pessoas concebem bem-estar e vida saudável, são entendidos aqui como transversais. Cecilio (2001) problematiza sobre as diferentes necessida- des expressas de diversos modos por pessoas de distintos estilos de vida, ou seja, entendendo que a maneira de viver reflete em diferentes necessidades de saúde. Assim, a rua como um lugar e um modo de vida, em meio à diversidade que a compõe, é coproduzida por transversalidades.

Pessoas em vivência de rua, tradicionalmente reconhecidas como moradores de rua, sem-teto, pessoas sem lar e população de rua ${ }^{2}$, constitui-se como um fenômeno presente em diversos períodos históricos, desde a Idade Média até os dias atuais. A vivência de rua, que antes era, predominantemente, espaço de expressão de loucura, rebeldia, ou de renúncia filosófica ou religiosa (Mollat, 1989), passa a atingir em maior escala, aqueles que gozam de saúde mental, mas que não conseguiram se inserir nos espaços de produção capitalista.

Uma característica importante da população em vivência de rua é o fato de ser predominantemente composta por homens (82\%) (Brasil, 2008a), o que pode indicar a existência de desigualdades nas relações de gênero nesses espaços. Tiene (2004) afirma que as mulheres são sempre em número menor do que os homens vivendo nessa condição, devido às desigualdades historicamente construídas entre ambos. A autora reflete sobre o fato de que, desde a Grécia Antiga, a sociedade convive com a divisão da vida em esfera pública e esfera privada, as quais definem papéis específicos para homens e mulheres. Os papeis femininos na sociedade sempre estiveram ligados ao cuidado com a prole e afazeres domésticos. Isso limitou as mulheres ao espaço físico e social da casa, cabendo aos homens a circulação nas ruas, nos espaços públicos. Entendemos que, talvez por isso, a vida nas ruas ainda tenha maior aderência de homens do que de mulheres.

Conforme Tiene (2004), o fenômeno histórico acima descrito se reflete também nas relações

Salientamos que "vivência de rua" ou "situação de rua" não são descritores em Ciências da Saúde na Biblioteca Virtual de Saúde, fonte de referência na construção das palavras-chaves de artigos científicos. 
estabelecidas na própria vivência de rua. Em outras palavras, as iniquidades de gênero afetam e são produzidas na interação entre as mulheres em vivência de rua e às demais pessoas desse meio, assim como os serviços e políticas criados para atendê-las. Desse modo, levamos em conta que pensar sobre a saúde das mulheres, de forma geral, já implica compreender o papel ocupado por elas nos espaços sociais e, principalmente, nos espaços de atenção à saúde (Brasil, 2004).

Pensando na diversidade de modos de conceber e cuidar da saúde presentes na vivência de rua, Matias e Francischini (2010) sugerem que as práticas e políticas voltadas a essa população, quando baseadas em uma suposta homogeneidade de suas características de grupo, podem vir a naturalizar sua condição, fazendo dessas pessoas prisioneiras de um estigma. Ainda, os autores supõem que uma concepção homogeneizada de vivência de rua corre o risco de que a própria população não se sinta incluída no grupo-alvo, levando ao fracasso das políticas públicas.

Além disso, entendemos que a integralidade depende da integração entre os diversos setores e saberes, como forma de suprir as carências e demandas das populações. Mais especificamente, ao falarmos em mulheres, inquietamo-nos com o fato de que as políticas de atenção específicas à população de rua não mencionam ações voltadas para sua saúde, parecendo negligenciar o fato de que essas são mulheres além de serem moradoras de rua. Ou seja, as políticas criadas para atender a grupos específicos demonstram certa desconectividade entre si.

Desse modo, como profissionais da área da saúde, comprometemo-nos com o conjunto de temas proposto a fim de produzirmos interrogantes e incitarmos transformações na maneira de se conceber a saúde das mulheres em vivência de rua. Para tanto, pontuamos como temática importante desse estudo as desigualdades de gênero presentes na vivência de rua e a forma como interferem no cuidado em saúde das participantes. Questionamo-nos sobre o quanto essa temática está inserida nas políticas de atenção à saúde das mulheres, em especial das que têm experiência com as ruas. Além disso, enfocamos a maneira como se dá o atendimento das instituições voltadas para a saúde dessa população.

\section{Método}

Adotamos uma perspectiva qualitativa na pesquisa, a qual se justifica, acima de tudo, pelo fato de que buscamos conhecer a experiência das participantes e suas interações sociais, dando espaço às especificidades. Além disso, reconhecemos, com base em Roso (2005), uma relação dialética entre a universalidade e a especificidade na produção de conhecimento, de modo que possamos trabalhar com campos universais, sem esquecer a importância das experiências singulares. Ao considerarmos a universalidade, não estamos nos referindo à generalizações amostrais e estatísticas, mas à possibilidade de generalização das proposições teóricas, isto é, aposta-se numa "generalização analítica" (Yin, 2010, p. 36).

Os dados referentes à pesquisa foram coletados através de observação participante e os registros feitos em diário de campo. A observação participante é um recurso para coleta de dados feita em campo, nos espaços de vivência e interação das pessoas. Através dele, o observador pode estabelecer um envolvimento com aquilo que está observando (Angrosino, 2009). As observações foram registradas em um diário de campo coletivo, escrito por todas(os) as(os) pesquisadoras(es), com acompanhamento da orientadora da pesquisa, recorrendo-se ao recurso do Google Drive ${ }^{\mathrm{TM}}$. Fizemos isso através de uma escrita implicada, quando evitamos uma cisão entre vivências de campo e produção de conhecimento. A escrita implicada é um recurso para trabalhar a incongruência. Através de uma releitura dessa escrita, de certo modo distanciada e reflexiva, as(os) pesquisadoras(es) pode se autoavaliar. Em congruência, registramos 
desde as informações obtidas, até nossos sentimentos e aquilo que não pudemos compreender num primeiro momento.

O trabalho de campo se deu em dois momentos. Inicialmente, procedemos com caminhadas pela cidade, com a finalidade de nos familiarizarmos com os espaços urbanos de um modo peculiar e, a partir daí, encontrarmos possíveis participantes. Em meio a tal processo, fizemos contatos com grupos e indivíduos em vivência de rua. Também contatamos informantes secundários como fiscais de trânsito e trabalhadores do comércio local, a fim de buscar informações e aproximação com a população alvo. O segundo momento consistiu em contatos diretos com duas mulheres, dentre as que encontramos durante as referidas caminhadas. Importa salientar que, apesar de termos observado a presença de várias mulheres em vivência de rua, poucas foram aquelas com as quais conseguimos um contato direto, e, dentre essas, apenas duas aceitaram participar da pesquisa.

A observação participante, enquanto técnica de produção de informações, se deu aliada à conversação corrente. Uma vez estabelecido contato e recebido o aceite de participação por parte de cada uma das mulheres, passamos a visitá-las, com frequência média de três vezes por semana. Durante tais visitas, além de observar a rotina das participantes, estabelecemos diálogos com as mesmas. Os elementos colhidos através dessas conversações foram igualmente registrados no diário de campo. Conforme os critérios estabelecidos para a pesquisa, ambas participantes são maiores de 18 anos e com mais de dois anos em vivência de rua. Estabelecemos diálogos, participamos de algumas de suas atividades e, na medida do possível, interagimos com o espaço geográfico onde as encontrávamos.

A realização da pesquisa seguiu a aprovação do projeto pelo Comitê de Ética em Pesquisa (CEP), da Universidade Federal de Santa Maria, sob Carta de Aprovação (CAE): 12475113.4.0000.5346. Seguiu, também, os critérios estabelecidos pela Resolução $n^{\circ}$ 466/12 do Conselho Nacional de Saúde (Brasil, 2012) e a Resolução no 16/2000 do Conselho Federal de Psicologia (2000). Reconhecemos o Termo de Consentimento Livre e Esclarecido (TCLE) como importante documento para a produção de informações com seres humanos, entretanto reavaliamos sua utilização neste estudo, mediante a justificativa de que se trata de um público bastante reticente em relação às instituições, e que, apesar de terem consentido verbalmente, demonstraram desconforto diante da proposta de assinar, ou até mesmo gravar em áudio, tal consentimento. Diante disso, uma notificação foi enviada ao CEP, explicando sobre os possíveis prejuízos da utilização do TCLE com o público específico desta pesquisa, a qual foi deferida.

Entre os meses de setembro e dezembro de 2013, realizamos 25 observações, contando caminhadas e visitas, com duração aproximada de uma hora cada. Ao final deste período, diminuímos gradativamente a frequência das visitas. Ainda que o término de coleta de dados em pesquisa qualitativa continue sendo uma questão e um desafio, entendemos que já conseguiríamos responder aos objetivos de nossa pesquisa e analisar as observações à luz dos teóricos escolhidos, embora estivéssemos cientes de que se continuássemos no campo, novas informações poderiam ser construídas.

Tentamos reconstruir as experiências das participantes a partir das observações e das narrativas produzidas em campo. Para tanto, inicialmente realizamos uma leitura flutuante do diário de campo, destacando as passagens significativas para o alcance dos objetivos propostos. Posteriormente, iniciamos o processo de organização dos dados: criação de campos culturais, de modo a orientar a leitura da análise.

Os campos culturais têm um caráter conceitual, ou seja, eles nos remetem ao teórico. Não são categorias, por não terem a intenção de classificar, catalogar, categorizar o fenômeno, mas pensá-los vinculados e fabricados pela cultura, a qual é sempre simbólica (Roso, 2010). Para a análise do mate- 
rial produzido, ancoramo-nos, principalmente, em uma abordagem psicossocial (Roso, 2005, 2010; Strey, 2012; Joffe, 2012; Villela, 2000; Jodelet, 1998), na qual o sujeito é concebido como sujeito dos discursos a que cada pessoa tem acesso em sua trajetória e processo de socialização, processo que não a sujeita fundamentalmente; as pessoas vivem a reinterpretar discursos em diversos contextos de sua vida (Paiva, 2013). Além disso, recorremos a autores que trabalham especificamente com a questão da vivência de rua (Tiene, 2004; Carneiro, Nogueira, Lanferini \& Martinelli, 1998; Gomes, 2006; Matias, 2011; Costa, 2005; Aristides \& Lima, 2009; Varanda \& Adorno, 2004).

A seguir, apresentamos as participantes principais deste estudo, com o uso de nomes fictícios, tanto para elas quanto para qualquer outra pessoa que possivelmente apareça nos relatos, a fim de manter sigilo sobre suas identidades. As apresentações têm por objetivo ressaltar as experiências em vivência de rua de cada uma das participantes. Os casos apresentados são distintos em suas características, no entanto possuem aspectos que devem ser considerados tanto nas especificidades, quanto nas similitudes. Essas duas histórias se distinguem e, em algum ponto, intersectam-se. Com base em Fonseca (1999), entendemos que é no vaivém dos pontos de encontro, que ressaltam as semelhanças e das divergências que mostram as especificidades, que temos a oportunidade de operacionalizar as sutilezas da análise social, tecendo representatividades. Para tanto, precisa-se situar os participantes em um contexto histórico e social, analisando as relações mais do que simplesmente os aspectos individuais da sua vivência.

\section{Contextos e Experiências em Vivência de Rua: Isabel e Irene}

Isabel é uma mulher de 25 anos, natural da cidade de realização da pesquisa, gestante no período em que realizamos o trabalho de campo. Vive há dez anos com seu cônjuge Osvaldo, de 35 anos, com quem tem dois filhos, ambos destituídos do poder familiar. Ele trabalha como pintor e cuidador de carros, e ela costuma acompanhá-lo nesse último serviço, permanecendo sentada na calçada enquanto ele trabalha.

Todas as visitas tiveram a presença e interação do companheiro, motivo pelo qual aparece em diversos momentos desta narrativa. Advertimos o leitor de que poderão surgir algumas contradições no discurso do casal, sobre as quais nem sempre buscamos saber a "verdade", já que o que importa para este estudo são olhares sobre os fenômenos, e não a veracidade dos fatos.

"No trecho" (SIC) ${ }^{3}$ (termo utilizado para referir-se à rua) há dois anos, Isabel conta que precisaram vender a casa onde viviam, o que, segundo Osvaldo, foi "por causa da pedra [crack]" (SIC). Ela nunca esteve em uma instituição de acolhimento, apesar de saber sobre o funcionamento e as regras de uma. Tece muitas críticas a esse tipo de instituição e à política de assistência social de maneira geral. Diz não recorrer à casa de passagem municipal devido a conter muitas "regrinhas" (SIC). Critica o fato de não poder beber e nem fumar lá dentro e de ter que chegar às 19 horas e sair às 6 horas da manhã. Para a participante, esta última é a mais incômoda das regras já que, cotidianamente, prefere dormir até mais tarde.

Apesar da não aderência às instituições, Isabel afirma nunca ter dormido na rua ou na calçada. Junto com o marido, costuma passar as noites no que chama de "mocós" (SIC) - locais abandonados (casas desocupadas ou construções abandonadas) onde conseguem estabelecer moradia provisória, guardar pertences e permanecer à noite com certa segurança. Esses locais, segundo a participante, geralmente estão mobiliados, contendo inclusive cobertores e eletrodomésticos. O tempo de permanência nos mesmos costuma ser curto, necessitando se mudar quando surgem problemas com

Utilizamos SIC (Segundo Informações Colhidas) para enfatizar que a expressão ou sequência discursiva é literal. 
a vizinhança. Conta que vive no "mocó" apenas com Osvaldo, já que a junção de muitas pessoas pode gerar desconforto na vizinhança, a qual poderia denunciá-los por invasão de espaço privado.

Sobre a vivência de rua, Isabel diz não se tratar de uma escolha, pois, em suas palavras, "ninguém gosta de morar na rua" (SIC). Porém, conclui dizendo que "ninguém gosta, mas se acostuma" (SIC). A participante afirma ter esperanças de se estabelecer em um domicílio, planejando alugar uma peça para morar com o marido e o filho que vai nascer. Dentre outros fatores, entendemos que esse desejo também está ligado a uma preocupação em ficar impedida, pela justiça, de permanecer com seu bebê.

A mesma preocupação é expressa pela participante quando relata a forma como busca atendimento na unidade de saúde. Apesar de viver no centro da cidade, prefere ir até o bairro onde mora seu pai para prosseguir com as consultas de pré-natal, ao invés de buscar uma unidade próxima do centro. Faz isso como estratégia para driblar a necessidade de comprovar endereço como condição para receber atendimentos. Isabel referencia o domicílio de seu pai, ao invés de relatar que vive nas ruas. Segundo ela, se contar sobre seu modo de vida, perde a guarda da criança logo após o nascimento, conforme aconteceu com outros dois filhos que teve anteriormente e que hoje estão vivendo com famílias adotivas por determinação judicial.

A participante manifesta críticas sobre o sistema de saúde ao se deparar com a dificuldade em conseguir um exame de ultrassonografia. Segundo ela, precisou pagar para fazer o exame em uma clínica particular, pois, apesar de ter direito ao mesmo, precisaria esperar muito tempo por uma vaga, correndo o risco de não consegui-la antes do nascimento da criança. Queixa-se, dizendo que "a saúde é muito pobre, ainda mais nesta cidade” (SIC).

A alimentação de Isabel é feita, em parte, nas ruas. Três vezes por semana, ela e demais pessoas em vivência de rua, recebem janta de uma casa espírita. Diz gostar da comida, chegando a comer a dela e a do marido, às vezes. Segundo ela, o cardápio é bastante variado. As outras refeições são feitas em um restaurante popular ou em algum restaurante comercial perto de onde permanecem durante o dia. Ainda, algumas vezes, fazem comida no "mocó" (SIC), usando álcool combustível, que lhes dão no posto de gasolina, para acender o fogo.

Cuidados com a alimentação, com a estética, e com a higiene são presentes no cotidiano de Isabel. Durante as visitas sempre a vimos bem vestida, com o cabelo preso e bem cuidado. A higiene pessoal é feita em diversos lugares: banheiro de estacionamento, banheiro da Corsan e demais banheiros públicos. Além disso, os "mocós" também servem para os cuidados pessoais. Isabel ainda relata que seu padrasto vive perto do "mocó", e que então, às vezes, vai à casa dele tomar banho, comer, e "até dormir" (SIC).

Em relação ao companheiro, Isabel parece vivenciar situações de conflito e dominação. Conforme relatos de uma informante - trabalhadora das redondezas, que conhecemos durante a primeira etapa do trabalho de campo, e que nos falou sobre o casal - os dois brigam bastante e Osvaldo chega a agredir Isabel fisicamente. Em contato com o casal, não observamos tais atos, no entanto foram diversos os momentos em que percebemos iniquidades na relação. Osvaldo se mostrou bastante dominador, determinando o modo como Isabel deveria se portar e emitindo opiniões de cunho machista, como, por exemplo, quando diz não querer que ela mantenha amizade com determinada mulher, por esta ser profissional do sexo. Além disso, costumava responder por ela, inibindo sua expressividade sobre alguns assuntos.

Presenciamos, ainda, o uso de bebidas alcoólicas e cigarros por parte de Isabel e Osvaldo. Em geral, ele bebia em mais volume ou uma bebida mais forte do que a dela e, consequentemente, tinha maiores alterações comportamentais, falando mais alto ou expressando euforia. Já Isabel sempre 
se manteve aparentemente sóbria enquanto conversava conosco.

É importante registrar alguns aspectos da interação entre a participante e a população em geral, tanto outras pessoas em vivência de rua, quanto moradores das redondezas e passantes. Em geral, as pessoas respondiam aos seus cumprimentos e às brincadeiras emitidas por Osvaldo e, muitas vezes, eram simpáticas com o casal, especialmente os moradores domiciliados naquela rua. Afirmando conhecer toda a rotina da vizinhança, Isabel parece ter boas relações com a mesma. Sobre as demais pessoas que vivem na rua, inicialmente dizem que "amigos, amigos" (SIC) não têm nesse meio, mas que possuem boas relações com os outros rapazes que ficam naquele mesmo ponto cuidando carros. Percebemos que na rua se estabelecem relações de ajuda e companheirismo, sobretudo quando se refere à comida. "Se um passa fome, o outro divide o que tem" (SIC), afirma Isabel.

A experiência da outra participante na pesquisa, Irene, é bastante diferente da anterior, em diversos de seus aspectos, desde a história de vida, até as necessidades em saúde e as estratégias de cuidado consigo. Apesar de não saber dizer a própria idade, pareceu-nos que possui em torno de 70 anos. Com aparência sofrida e olhar terno, Irene costuma passar as manhãs e parte das tardes na porta de um banco, sentada no chão, com uma caneca na mão (onde arrecada esmolas), uma bolsa à meia espalda (onde guarda o dinheiro que é posto na caneca), uma sacola de alimentos ao lado e um boné na cabeça.

Começamos a visitá-la no final do inverno, em dias frios e chuvosos. Raramente esses foram motivos para que ela quebrasse a rotina de chegar às oito da manhã, e sair entre 12 e 15 horas da tarde. O mesmo acontecendo nos dias quentes, já nas últimas visitas, feitas no verão. Reconhecemos que a participante segue uma organização para lidar com as variações climáticas. O local onde permanece é sempre o mesmo, ao lado de fora da porta da agência bancária. Ali pudemos perceber que a temperatura é afetada pela refrigeração do estabelecimento, mantendo-se aquecida no inverno, e refrescante no verão. Além disso, possui uma aba capaz de protegê-la de chuvas fracas. A retirada até às 15 horas também nos parece estratégica, já que é quando o sol começa a invadir aquele espaço.

Apesar de possuir uma casa, onde dorme e passa os finais de semana, segundo informa - não tivemos acesso à mesma -, a permanência na rua segue uma rotina que raramente é alterada. Parece ser mais que um espaço de sobrevivência, configurando-se como um lugar de moradia, ou ainda, um local de trabalho. Além disso, Irene estabelece uma relação de pertencimento e propriedade com o lugar, estando ali há mais de 30 anos, alimentando-se no local e expulsando a quem lhe causa incômodos. Segundo informantes —uma fiscal de trânsito que contatamos enquanto circulávamos pelas redondezas, e uma trabalhadora do banco diante do qual permanecia Irene- houve muitas tentativas de recolhimento institucional, no entanto Irene sempre resistiu, permanecendo no local. Além de ser tratada como uma pessoa em vivência de rua, tanto pelas instituições, quanto pela sociedade em geral, torna-se evidente que Irene está exposta às dificuldades e violências características de quem vive nas ruas.

Parece-nos que a rotina da rua, para Irene, é tão importante quanto à rotina da casa. No universo da rua, a participante expressa conforto e familiaridade, como se aquele espaço fosse seu e como se seu corpo pertencesse àquele espaço. Durante uma visita, ela comia um pastel e derrubava pedaços na calçada, os quais juntava, com a ponta dos dedos, para comer. Em outros momentos, a observamos atirando seu próprio lixo para longe de si, como se um círculo imaginário em volta dela compusesse seu espaço.

Os cuidados em saúde de Irene seguem estratégias próprias, dispensando os procedimentos institucionais. Diz não buscar atendimento em serviços de saúde e, quando interrogada sobre o agente comunitário de saúde de seu bairro, dá 
a entender que não sabe do que se trata, ou seja, possivelmente não seja atendida pelo Programa de Agentes Comunitários de Saúde (PACS). Segundo ela, compra remédios quando necessita, e tem uma vizinha que the cuida em caso de ficar doente. Essa vizinha parece exercer papel importante na vida da participante, sendo citada em diversas observações. Em alguns momentos Irene se refere a ela como uma amiga, em outros diz ser apenas uma vizinha, e ainda em outros, diz se tratar de alguém a quem paga para que faça sua comida.

Um fato ocorrido durante as observações foi bastante significativo para entendermos aspectos da relação de Irene com os serviços de saúde. Em uma das visitas, a participante nos mostra que tem uma ferida ensanguentada no pé. Preocupamo-nos, pois, apesar de ser apenas um corte, tomava toda a parte de baixo do dedo maior, o que poderia causar dores ao caminhar. Perguntamos se iria procurar um serviço de saúde, ao que responde negativamente, afirmando que a vizinha lhe havia feito um curativo e logo iria sarar. Ainda preocupadas, oferecemo-nos para buscar ajuda e ela aceitou que o pedíssemos em uma farmácia, e depois na unidade de saúde mais próxima, porém deixou claro que não iria a nenhum desses locais. Somente aceitaria o atendimento se fosse feito ali, no local onde se encontrava. Em nenhum desses locais prestava-se esse tipo de atendimento e, quando demos a notícia a Irene, ela pareceu não se importar, dizendo que estava bem, pois não sentia febre. Assim, demonstra que a febre é um alerta de enfermidade relevante para ela. Em uma próxima visita, mostra o ferimento já cicatrizado. Perguntamos, então, quais procedimentos havia adotado, ao que responde, simplesmente, "eu me curei sozinha" (SIC).

\section{Relação com a(o) Outra(o) na Rua}

A relação entre as participantes e a(o) Outra(o) é um campo cultural bastante saliente dentre os dados produzidos nesta pesquisa. Além disso, en- tendemos que merece atenção devido à influência que essas relações exercem sobre os modos de se compreender e cuidar da saúde. Iniciamos essa discussão olhando para como as mulheres participantes deste estudo são tratadas pelo Outro (incluindo nós pesquisadoras) que circula pelos espaços urbanos. Em meio a isso, discutimos sobre como as relações de gênero perpassam essas interações e interferem no cuidado em saúde. Por fim, voltamos nosso olhar para a relação entre as participantes do estudo e os serviços de atenção à saúde das mesmas.

O cheiro de urina, os restos de comida, as roupas e colchões observados durante o trabalho de campo, são símbolos de uma "alteridade de dentro", a qual é definida por Jodelet (1998) através de uma diferença, neste caso, ligada a uma pertença de grupo. Essa alteridade distingue as pessoas no seio de um conjunto social ou cultural, podendo gerar mal-estar ou ameaça.

Os referidos símbolos são citados na bibliografia consultada (Matias, 2011; Carneiro, Nogueira, Lanferini \& Martinelli, 1998) como presenças no ambiente urbano, que causam reações de rejeição e insegurança por parte da vizinhança. De acordo com Matias (2011), o estigma da vida nas ruas é realçado pelos signos de sua presença. Nos casos estudados, em um primeiro momento, notamos interações entre as participantes e os residentes próximos aos seus locais de estadia. No entanto, tais interações provinham, em geral, de ações caridosas ou breves cumprimentos, raramente chegando a se estabelecer uma conversa.

Devido ao longo tempo que permanecem no local, Isabel e o companheiro já são conhecidos pelas pessoas que ali vivem e trabalham, estando a par das suas rotinas, causa principal das interações. No entanto, quando interrogada sobre como é a relação com as pessoas que por ali circulam, a participante diz que se sente ignorada. Enfatiza que "as pessoas passam e nem olham pro morador de rua" (SIC).

O caso de Irene não se difere, em essência, do de Isabel. Numa das primeiras visitas, conversa- 
mos com uma trabalhadora do banco, a qual se referiu amigavelmente à participante. No entanto, logo depois, começa a expressar nas entrelinhas o desconforto gerado pela presença daquela mulher, o que demonstra uma superficialidade na interação entre ambas. A trabalhadora do banco pareceu preocupada em contar o que sabia sobre a vida de Irene, ressaltando os inconvenientes que causa por permanecer no local. Queixa-se de que muitos clientes se incomodam com a presença dela, e que algumas pessoas já caíram ao saírem do banco ao tropeçarem nas suas pernas esticadas na calçada.

A superficialidade interacional por parte dos passantes foi observada por nós, tomando contornos bem visíveis: o contato dos passantes com Irene nunca era mais que um olhar ou uma esmola. Durante o tempo de coleta, não conhecemos ninguém que estabelecesse uma relação ou um diálogo com ela, que conhecesse aspectos da sua vida para além de suposições.

Galvani (2008) já se referiu a esses contatos estabelecidos nos itinerários das ruas como potenciais geradores de ganhos para as pessoas em vivência de rua, os quais, neste estudo, apresentaram-se como doações de alimentos e esmolas. No entanto, apesar dessas breves interações entre as participantes e seus vizinhos e passantes, parece haver um limite claro, que define quem é da rua e quem não é: de um lado estão os que utilizam as ruas para circulação, de outro, os que vivem nela. Isso nos remete à ideia de uma comunidade esquartejada. Os espaços rua e casa são separados imaginariamente: conforme Matias (2011), as populações em vivência de rua são automaticamente apartadas do laço social que liga as pessoas nos espaços urbanos.

Pode existir uma linha que liga os integrantes desse cenário, no entanto, a Isabel e Irene não é permitido ultrapassar os limites que esclarecem as diferenças de posição entre elas e o resto da sociedade. De acordo com Jodelet (1998), esses limites servem ao estabelecimento de uma distância para com o diferente. Nessa lógica, eles precisam ser rigidamente respeitados para que se mantenha a desconfiança em relação ao diferente, e assim não se alcance a aproximação que a semelhança induz.

Tais limites, nesse caso, parecem ser estabelecidos através de projeções degradantes por parte dos demais atores sociais sobre as pessoas em vivência de rua. Elas seriam o que Joffe (2012, p.255) chamou de "outro' total”: um grupo específico sobre o qual a ideologia dominante da sociedade costuma propagar imagens de ações socialmente inaceitáveis.

No processo de formação de identidade, as pessoas buscam um controle e um sentido de comunidade. Ao dissociarem os objetos do mundo externo em grupos bons e grupos maus, projetam o medo na realidade externa, na(o) Outra(o), e defendem o seu grupo como o que se comporta aceitavelmente (Joffe, 2012). Nesse sentido, ao passo que o grupo participante da pesquisa é tratado pelos demais como a(o) Outra(o) “inaceitável”, também ele próprio se dissocia em busca de uma identificação com o grupo “aceitável”. Isabel, em diversos momentos, chama atenção para as características que assemelham ela e o companheiro às pessoas que vivem em domicílio fixo, e os desassemelham aos que vivem nas ruas. Faz questão de ressaltar a aparência física como uma diferença entre eles e as demais pessoas em vivência de rua, argumentando que se banham e andam vestidos. Com isso percebemos a tentativa de um distanciamento daquela imagem degradante projetada sobre as populações em vivência de rua, e uma busca de identificação com grupos dominantes.

A partir desse entendimento, questionamo-nos sobre quão presentes se fazem os modelos de consumo e produção capitalistas na vida dessas pessoas. Ao passo que se distanciam dos estereótipos do bem viver definidos por uma sociedade capitalista, movimentam-se em prol de uma semelhança com os mesmos. Quiçá isso tenha a ver com o fato de que fazem parte dessa sociedade, não estando totalmente excluídos dela. Levando em conta que todo fenômeno está ligado a uma totalidade, 
Guareschi (1992) defende uma relação intrínseca e imprescindível entre o que se poderia chamar de excluído e o incluído. Desse modo, não existiria uma categoria onde se encaixassem os excluídos, já que todos fazem parte e se interdependem na sociedade. Com base nessa compreensão, entendemos que o que existe são diferenças entre as pessoas e grupos, desigualdades nas suas relações e iniquidades no acesso a bens e serviços.

\section{Efeitos das Relações de Gênero no Cuidado}

A partir da análise das relações estabelecidas entre as participantes e a(o) Outra(o) na rua, salientam-se as questões de gênero. De maneira mais profunda, entendemos que gênero é um campo cultural que atravessa todos os outros presentes neste estudo, assim como é um elemento transversal que perpassa a instituição saúde.

Autores como Strey (2012) e Roso (2005) demonstram que as relações opressivas de gênero são capazes de impactar significativamente o modo como as mulheres vivenciam sua saúde. Strey (2012) salienta que as questões de gênero nunca são somente questões de gênero. A autora se refere à transversalidade entre esse campo e outros tantos que compõem a singularidade da vida de uma pessoa: questões étnicas, de classe, de idade, de educação, de religião, de cultura e, podemos acrescentar, de modos de morar, de comer, de se manter financeiramente e de se relacionar com as(os) outras(os).

A experiência da participante Isabel, conforme já relatado nas narrativas, expressa claramente tais elementos transversais. O modo de ser e se conceber como mulher, além de como é vista enquanto tal interfere diretamente na maneira como leva a vida e cuida da própria saúde. O discurso do companheiro Osvaldo já demonstra as injustiças dessa relação. Inicialmente, ele reclama do excesso de proteção que existe sobre as mulheres de um modo geral, referindo-se à Lei Maria da
Penha (Brasil, 2006), a qual protege as mulheres contra violência. Depois, diretamente em relação à Isabel, demonstra domínio sobre sua expressividade, inibindo suas opiniões. Sentimos, muitas vezes, que ela deixava de responder às nossas interrogações ou de defender sua posição diante de algum assunto, pois ele respondia por ela. Apesar de Isabel, algumas vezes, opor-se às ideias do marido, o fazia de maneira discreta.

Apesar de não havermos presenciado nenhuma violência física por parte de Osvaldo em relação à Isabel, valorizamos o discurso da informante que nos relatou havê-lo presenciado, entendendo que isso faz parte da cotidianidade da vivência dessas mulheres. Além disso, a violência relatada foi, muitas vezes, sugerida no discurso do companheiro de Isabel. As mulheres são muito protegidas, na opinião dele, pois, conforme suas palavras, "mesmo tendo razão - pegando a mulher com outro- o homem não pode dar um soco na boca dela, que enquadra na lei Maria da Penha" (SIC). Outra vez reclama que, mesmo a mulher brigando "com o cara" (SIC) que está cansado de trabalhar, ele não pode bater nela, porque "dá Maria da Penha" (SIC).

Desde aí, questionamo-nos sobre a rua e suas peculiaridades, em contrapartida à visão comum de que na rua é sempre igual e nela todas as relações são iguais. Assim como a rua pode representar um refúgio de violências domiciliares (Tiene, 2004), também nela podem estar se desenvolvendo relações opressivas e violentas. Além disso, ao passo que uma companhia pode representar segurança e companheirismo à mulher em vivência de rua, também podem estar se estabelecendo atos de violência doméstica similares àquelas observadas em algumas famílias que vivem em domicílio. Sob esse aspecto, podemos sinalizar uma possível incompletude nas políticas públicas quando deixam de levar em conta aspectos singulares da própria violência ${ }^{4}$. Queremos dizer que, ao ser a rua um

4 Programa de Prevenção, Assistência e Combate à Violência Contra a Mulher (Brasil, 2003). 
espaço onde se realizam atos de violência conjugal contra a mulher, é necessário que os serviços olhem para essa questão nos espaços das ruas —além de todos os outros espaços possíveis, e não apenas os restrinjam ao doméstico-.

Além das iniquidades de gênero expressas nas relações cotidianas e pessoais das participantes, também percebemos a presença marcante dessas nas ações e serviços de saúde que atendem à população em vivência de rua. Ainda hoje, conforme Villela (2000), as ações de saúde coletiva nas unidades básicas de saúde, em sua maioria, seguem uma proposta de atenção materno-infantil. A gestação era o aspecto que ligava Isabel a tais serviços, devido às consultas de pré-natal. No entanto, mais uma vez, observamos falta de integralidade no cuidado.

Considerando que a integralidade implica um olhar sobre o sujeito integral, em todas as suas necessidades de saúde (Brasil, 2000), questionamos o fato de que Isabel era atendida em um estabelecimento que sequer conhecia suas necessidades e condições de vida. A participante declarava endereço quando, na verdade, vive nas ruas. Se, por um lado, essa é uma estratégia utilizada por ela para lidar com uma limitação imposta pelo próprio sistema, por outro, o serviço está deixando de atendê-la em suas necessidades, já que possivelmente desconhece outros aspectos que incidem sobre sua saúde. Em outras palavras, a própria burocratização do serviço pode servir como uma barreira para o cuidado. Se por um lado entendemos a necessidade dos serviços de colherem informações sociodemográficas, por outro esse mesmo processo pode dificultar o atendimento integral à saúde.

$\mathrm{O}$ fato de que Isabel recorre ao serviço somente para atenção gestacional, mais uma vez demonstra que a questão reprodutiva vem a ser mais valorizada que as demais que envolvem a saúde de uma mulher. Desse modo, o acesso aos serviços, em especial para as mulheres em vivência de rua, parece seguir um caminho coberto de obstáculos, desde as questões morais até as institucionais e normativas.

\section{Da Iniquidade de Acesso aos Serviços de Atenção à Saúde à Necessidade de Políticas Públicas Equitativas}

Neste campo cultural, retomamos muitas das experiências e observações sinalizadas nos campos anteriores, justamente porque entendemos os campos culturais interligados um com o outro. Os contextos e experiências de Isabel e Irene coproduzem as relação com a(o) Outra(o) na rua, engendram efeitos no cuidado em saúde e, possivelmente, derivam da iniquidade de acesso aos serviços de atenção à saúde e da carência de políticas públicas equitativas.

De um modo geral, a população em vivência de rua parece passar por graves condições de risco à saúde física e mental. No entanto, os sentidos atribuídos a estar saudável não são estanques, apresentando-se, nesta população, diferentes, muitas vezes, de como é para pessoas que têm os serviços de saúde mais próximos do seu cotidiano. Costa (2005) evidencia a precariedade de adequação dos serviços disponíveis nos municípios através do SUS, para o atendimento das pessoas em vivência de rua.

A ausência de documento, de comprovantes de residência, dentre outras limitações que os impedem de seguir os protocolos de cadastramento convencionais, costuma apresentar-se como barreiras ao acesso das pessoas em vivência de rua aos serviços de saúde. Costa (2005) se refere à solicitação de comprovante de residência para agendamento de consulta como uma realidade vivenciada pelas pessoas em vivência de rua de forma excludente, já que as mesmas, em geral, não possuem moradia fixa. Nos casos discutidos em nossa pesquisa, tanto no de Isabel como de Irene, constata-se o enfrentamento a tais barreiras para atendimento em saúde. Isabel cria estratégias para 
lidar com a necessidade de comprovar residência fixa, diante da ameaça de perder a guarda do filho, e assim resiste ao controle institucional. Irene, por sua vez, prefere tentar ajuda para fazer curativo em uma farmácia do que recorrer ao serviço público de saúde e, quando não consegue, cuida-se sozinha ou com a ajuda da vizinha.

O enfrentamento de barreiras não apenas designa estratégias para lidar com serviços de saúde, que parecem não auxiliar no acesso da população de rua a eles, mas indica, ainda que implicitamente, uma ideia das participantes de não sentir necessidade de buscar os serviços de saúde porque elas conseguem, sozinhas, resolver seus problemas de saúde.

Tanto em relação ao corpo, como comer pedaços de comida juntados da calçada, quanto em relação ao meio, como jogar lixo no chão, as atitudes de Irene fogem ao que é moralmente aceito na sociedade e na época em que vivemos. Num primeiro momento, tais atitudes são capazes de causar espanto e preocupação para quem as observa. No entanto, entendemos que esses sentimentos se relacionam a conceitos morais estabelecidos através de representações sobre saúde e doença. Já para Irene, aquilo que nos parece descuido, pode significar justamente uma forma de cuidado, na medida em que organiza, à sua maneira, o seu espaço de permanência. Assim, em relação ao modo de viver saudável, as participantes do estudo nos mostram que os sinais de bem-estar e adoecimento não são os mesmos para todas as pessoas, eles variam conforme as condições de vida e as representações sociais.

A busca por atendimento institucionalizado como um último recurso para a população em vivência de rua foi visualizada na produção teórica consultada por nós (Aristides \& Lima, 2009, Varanda \& Adorno, 2004), o que vem ao encontro do que observamos neste estudo. As estratégias adotadas pelas participantes para cuidarem de si, em geral, descartam os procedimentos institucio- nalizados. Muito raramente se referem a atendimentos médicos e uso de medicamentos, exceto no caso de Isabel, já relatado anteriormente, em que busca atendimento devido à gestação. Isabel e o companheiro negam a necessidade de atendimentos desse tipo, já que reconhecem a bebida alcoólica como capaz de prevenir doenças. Do mesmo modo, Irene rechaça a ideia de buscar uma unidade de saúde para fazer curativo no pé ferido e depois conta ter se curado sozinha.

Apesar de as participantes não reconhecerem as instituições de saúde como um recurso principal de atenção e cuidado, houve momentos em que esse recurso foi utilizado ou, ao menos, mencionado como uma possibilidade. Desde aí, entendemos a importância que têm tais instituições, mesmo que nosso estudo indique que elas possam estar tendo baixa eficiência em receber as pessoas em vivência de rua como parte do seu público.

Conforme Varanda e Adorno (2004), o escasso acesso às instituições de atendimento pode gerar um acúmulo de problemas de saúde, os quais somente serão tratados quando já em estado avançado. Entendemos que se, por um lado, as pessoas em vivência de rua possuem necessidades particulares e estratégias próprias de cuidado em saúde, por outro, a falta de atenção que respeite tais características pode vir a gerar sofrimento e menos qualidade de vida a essas pessoas.

De acordo com nossas observações, além de as pessoas em vivência de rua não costumarem aceder aos serviços de saúde, tampouco as participantes se sentem fazendo parte das instituições e políticas públicas criadas em nome das pessoas em "situação de rua" (conforme denominação nos documentos oficiais do Ministério da Saúde). Muitas vezes, nem mesmo ocupam um lugar na vida dessas pessoas, não representando espaços de acolhida e segurança. Desde aí, refletimos sobre a utilidade de tais aparatos, já que são criados sob um discurso de cuidado às pessoas em vivência de rua, ou à população de um modo geral, visando 
integralidade na atenção, mas essas os desconhecem ou negam sua participação na construção e utilização dos mesmos.

A integralidade, enquanto um princípio do sus, refere-se a uma resistência à dicotomização das práticas em saúde. No entanto, ainda hoje, apesar dos avanços do sistema de saúde, essa dicotomia é bastante presente. Mesmo que atualmente tenhamos adotado um sistema que amenize as fronteiras entre serviços de saúde pública e serviços assistenciais, deparamo-nos com situações em que o acesso dos usuários é dificultado, devido a questões políticas que, de acordo com Mattos (2006), cindem os espaços de atenção. Essa é uma das hipóteses para o entendimento sobre o motivo da incoerência entre demandas e funcionamento dos serviços.

Em ambos os casos é muito saliente essa dicotomização. A maternidade de Isabel é um exemplo disso, quando se percebe o quanto parece estar descolada dos seus demais aspectos e determinantes de saúde. Assim, entendemos que os serviços estão mais presos às normas e procedimentos organizacionais do que ao cuidado em si.

Cecilio (2001) lembra que há diferenças nas necessidades de consumo de determinadas tecnologias de saúde, assim como diferenças nas necessidades ligadas às condições de vida e diferenças nas necessidades de construção da autonomia no modo de levar a vida. Assim, estabelecer políticas públicas equitativas significa "estabelecer procedimentos, formas de atendimento e diagnóstico flexíveis, que considerem, inclusive, a atenção extramuros ou em meio aberto estendendo o serviço de saúde a essa população" (Varanda \& Adorno, 2004, p. 68).

\section{Conclusão}

Entendendo que a saúde é um conceito amplo e de difícil fixação, a realização deste estudo nos levou à compreensão de que são diversos os aspectos transversais da vida dos sujeitos que impactam a sua saúde, desde os mais individuais, até os que dizem da coletividade e do social, com os quais estão envolvidos. No caso da vivência de rua, objeto deste estudo, suas peculiaridades se convertem em questões capazes de afetar a saúde e o modo de se cuidar das participantes.

Considerando que as participantes deste estudo possuem vínculos bem estabelecidos com os locais de permanência/moradia, as interações cotidianas incluem a vizinhança residente e/ou trabalhadora das proximidades, de quem recebem ações caridosas, alimentos e breves cumprimentos. Já com os passantes, raramente existe qualquer tipo de interação ou reconhecimento. Em ambos os casos, se torna evidente um processo de cisão social, ou seja, mesmo que a sociedade reconheça as pessoas em vivência de rua, trata de garantir limites claros, que definem quem é da rua e quem não é, através de projeções degradantes.

As relações de gênero se salientaram como um campo de análise que atravessa todos os demais. Desde as relações próximas e pessoais até as institucionais se mostraram permeadas pelas iniquidades de gênero, às quais estão submetidas as mulheres de um modo geral. Violência conjugal, dominação, valorização dos aspectos reprodutivos sobre a saúde de uma forma geral, foram algumas questões observadas, capazes de dificultar o cuidado integral em saúde dessas mulheres. Questões essas que merecem atenção especial nas políticas públicas e seus aspectos referentes às mulheres em vivência de rua.

Analisamos a relação das participantes com os serviços de atenção à sua saúde como um campo fabricado pela transversalidade. Apesar da importância das instituições no cuidado em saúde das pessoas em vivência de rua, estas têm buscado estratégias que as dispensam. As participantes do estudo raramente buscam atendimento institucionalizado, preferindo, muitas vezes, utilizar-se de métodos alternativos para tratarem e evitarem enfermidades. 
Não deixamos de considerar que as políticas atuais têm apresentado constantes melhoras no atendimento à saúde das minorias. Criam-se espaços e mecanismo de atenção, cada vez mais voltados para a integralidade e integração entre os diversos setores. Além disso, levamos em conta que as minorias também têm seu papel ativo na resolução de problemas e na criação de estratégias para lidar com as dificuldades impostas pela organização do sistema.

Concluímos, então, que o público participante desta pesquisa representa uma população bastante diversa em suas características, adotando variadas estratégias de cuidado em saúde. Além disso, é complexa nas suas necessidades, e demanda cuidados que levem em conta uma variedade de interpenetrações, especialmente aquelas que se referem às interações e relações estabelecidas nos meios onde vivem.

\section{Referências}

Altoé, S. (2004). René Lourau: analista institucional em tempo integral. São Paulo: Hucitec.

Angrosino, M. (2009). Etnografia e observação participante. (Coleção Pesquisa Qualitativa, U. Flick, Coord., J. Fonseca, Trad.). Porto Alegre: Artmed.

Aristides, J. L., \& Lima, J. V. C. (2009). Processo saúde-doença da população em situação de rua. Revista Espaço para a Saúde, 10(2): 43-52. Recuperado de http://www.ccs.uel.br/espacopara saude/v10n2/Artigo7.pdf

Bondía, J. L. (2002). Notas sobre a experiência e o saber de experiência. Revista Brasileira de Educação, 19, 20-28. doi: 10.1590/S141324782002000100003.

Brasil (2000). Sistema Único de Saúde (SUS): Princípios e conquistas. Brasília, DF: Ministério da Saúde.

Brasil (2003). Plano nacional: diálogos sobre violência doméstica e de gênero: construindo políti- cas públicas. Brasília, DF: Secretaria Especial de Políticas para as Mulheres - Programa de prevenção, assistência, e combate à violência contra a mulher.

Brasil (2004). Política Nacional de Atenção Integral à Saúde da Mulher: Princípios e Diretrizes. Brasília, DF: Ministério da Saúde.

Brasil, Presidência da República, Casa Civil, Subchefia para assuntos Jurídicos. Lei n ${ }^{\circ}$ 11.340/2006 (2006). Recuperado de http://www.planalto.gov. br/ccivil 03/ ato2004-2006/2006/lei/111340. htm

Brasil (2008a). Pesquisa Nacional sobre População em Situação de Rua. Brasília, DF: Ministério do Desenvolvimento Social e Combate à Fome.

Brasil, Conselho Nacional de Saúde. Resolução $N^{\circ}$ 466/12. Sobre Pesquisa Envolvendo Seres Humanos. (2012).

Carneiro, N. Jr., Nogueira, E. A., Lanferini, G. M., Ali, D. A., Martinelli, M. (1998). Serviços de saúde e população de rua: Contribuição para um debate. Saúde \& Sociedade, 7(2): 4762. doi: 10.1590/S0104-12901998000200005 Recuperado de http://www.scielo.br/scielo. php?pid=S0104=12901998000200005-\&scriptsci_arttext

Cecilio, L. C. O. (2001). As necessidades de saúde como conceito estruturante na luta pela integralidade e eqüidade na atenção à saúde. In R. Pinheiro \& R. A. Mattos (Eds.). Os sentidos da integralidade na atenção e no cuidado à saúde (pp. 113-126). Rio de Janeiro: IMS/UERJ - ABRASCO.

Costa, A. P. M. (2005). População em situação de rua: Contextualização e caracterização. Textos \& Contextos, 4(1), 1-15.

Fonseca, C. (1999). Quando cada caso NÃo é um caso: Pesquisa etnográfica em educação. Revista Brasileira de Educação, 10, 58-78.

Galvani, D. (2008). Pessoas em situação de rua na cidade de São Paulo: Itinerários e estratégias na construção de redes sociais e identidades. 
(Dissertação de mestrado em Ciências da Reabilitação, Faculdade de Medicina da Universidade de São Paulo, São Paulo).

Gomes, R. C. M. (2006). Gente-Caracol: A cidade contemporânea e o habitar as ruas. (Dissertação de mestrado em Psicologia Social e Institucional, Instituto de Psicologia da Universidade Federal do Rio Grande do Sul, Porto Alegre).

Guareschi, P. A. (1992). A categoria "Excluídos". Psicologia: Ciência e Profissão, 12(3-4): 4-11. doi: 10.1590/S1414-98931992000300002

IBGE. (2014). Censo demográfico 2010. Resultados. Brasília, DF: Instituto Brasileiro de Geografia e Estatística.

Jodelet, D. (1998). A Alteridade como produto e processo psicossocial. In A. Arruda (Ed.). Representando a alteridade, (pp. 47-67). Petrópolis, RJ: Vozes.

Joffe, H. (2012). "Eu não", "o meu grupo não": Representações sociais transculturais da Aids. In P. Guareschi \& S. Jovchelovitch (Eds.). Textos em Representações Sociais. 13. Ed, (pp. 297321). Petrópolis: Vozes.

Matias, H. J. D., \& Francischini, R. (2010). Desafios da etnografia com jovens em situação de rua: A entrada em campo. Psicologia: Reflexão e Crítica, Porto Alegre, 23(2), 243-252. doi: 10.1590/S0102-79722010000200006.

Matias, H. J. D. (2011). Jovens em situação de rua: Espaço, tempo, negociações de sentido. Psicologia \& Sociedade, 23(2), 237-247. doi: 10.1590/ S0102-71822011000200004

Mollat, M. (1089). Os pobres na Idade Média. Rio de Janeiro: Ed Campus, 1989.

Paiva, V. S. F. (2013). Psicologia na saúde: sociopsicológica ou psicossocial? Inovações do campo no contexto da resposta brasileira à AIDS. Temas em Psicologia, 21(3), 531-549. Recuperado de http://pepsic.bvsalud.org/scielo.php?script=sci arttext\&pid=S1413-389X2013000300002\&ln$\mathrm{g}=$ pt\&tlng=pt. 10.9788/TP2013.3-EE00-PT.

Quiroga, J., \& Novo, M. (2009). Elas da rua: população em situação de rua e questão de gênero. In:
Brasil, Ministério do Desenvolvimento Social e Combate à Fome. Rua: aprendendo a contar. Pesquisa Nacional sobre a população em situação de rua, (pp. 157-172.) Brasília, DF: MDS; Secretaria de Avaliação e Gestão da Informação; Secretaria Nacional de Assistência Social. Rocha, D., \& Deusdará, B. (2010). Contribuições da Análise Institucional para uma abordagem das práticas linguageiras: A noção de implicação na pesquisa de campo. Cadernos de Letras da UFF. Dossiê: Letras, linguística e suas interfaces, 40, 47-73.

Roso, A. (2005). Cultura sexual e reprodutiva em tempos de Aids: Análise transcultural dos discursos relacionados à transmissão materno-infantil do HIV-1. (Tese de Doutorado, Pontifícia Universidade Católica do Rio Grande do Sul, Programa de Pós-graduação em Psicologia, Porto Alegre).

Roso, A. (2010). Mulheres latinas e transmissão vertical do HIV: Visão dos profissionais da saúde que atendem mulheres soropositivas nos Estados Unidos. Revista Interamericana de Psicologia, 44(2), 332-341.

Strey, M. (2012). Apresentação. In M. Strey (Ed.). Gênero e ciclos vitais: Desafios, problematização e perspectivas (Série Gênero e Contemporaneidade, 8), (pp. 7-21). Porto Alegre, RS: Edipurs.

Tiene, I. (2004). Mulher moradora na rua: Entre vivências e políticas sociais. Campinas, SP: Alinea.

Varanda, W., \& Adorno, R. C. F. (2004). Descartáveis urbanos: Discutindo a complexidade da população de rua e o desafio para políticas de saúde. Saúde \& Sociedade, 13(1), 56-69. doi: 10.1590/S0104-12902004000100007

Villela, W. (2000). Saúde integral, reprodutiva e sexual da mulher: Redefinindo o objeto de trabalho a partir do conceito de gênero e da Conferência Internacional sobre População e Desenvolvimento. In M. J. O. Araújo (Ed.). Saúde das mulheres: Experiência e prática do 
Coletivo Feminista Sexualidade e Saúde, pp. (pp. 23-32). São Paulo: Coletivo Feminista Sexualidade e Saúde.

Yin, R.K. (2010). Estudo de caso. Planejamento e métodos. (4.ed.). Porto Alegre: Bookman.

Recebido: setembro 9, 2014

Aprovado: agosto 3, 2016 
